\title{
High-throughput phenotyping for trait detection in vineyards
}

\author{
Anna Kicherer, Katja Herzog, and Reinhard Töpfer \\ JKI Institute for Grapevine Breeding Geilweilerhof, 76833 Siebeldingen, Germany
}

\begin{abstract}
Recently several papers appeared describing initial steps for novel phenotyping technologies in grapevine management, research and breeding. Kicherer and coworkers were the first using a robotic device which permits to follow a GPS track, stopping in the vineyard automatically at defined coordinates. By doing so the system stops face to face in front of a desired grapevine accession, takes a set of photos and moves to the next position repeating the actions. The acquired data of a single grapevine are stored and afterwards transferred into a database. First traits have been evaluated by the new technique. The current phenotyping possibilities are discussed.
\end{abstract}

\section{Introduction}

About a decade ago marker assisted selection (MAS) was introduced into grapevine breeding programs around the world [1, 2]. MAS marked a paradigm shift for resistance breeding against powdery and downy mildew the most devastating grapevine diseases. This novel tool permits a fast and very efficient selection of resistance loci. Due to MAS the aims of grapevine breeders changed towards the combination of two or more loci against each mildew pathogen (stacking of defined resistance loci) to try to select for higher and more durable resistances (for review: [3]).

The great progress in resistance breeding based on the application of MAS, created a desire for markers for additional traits like other stresses, phenology, yield, or even quality. Some of these traits rely on adult plants in the vineyard as the natural environment rather than using greenhouse plants. In such conditions the evaluation of traits becomes more difficult and is generally done by skilled people estimating traits e.g. based on OIV descriptors or other scales. This kind of work is very labor intensive and suffers from limited throughput as well as from subjectivity. In order to speed up the evaluation process novel technologies are required using sensors and robotics to phenotype grapevine in the field.

During recent years several groups developed techniques for phenotyping using different sensors techniques. Visible light (RGB and monochrome images) [4-7], fluorescence [8], thermal $[9,10]$ and spectral [11-13] sensing approaches as well as 3D approaches $[14,15]$ have been implemented in viticulture recently. The JKI contribution in this context on using visible light sensors is described below.

\section{Materials and methods}

PHENObot (Fig. 1) is an automatic robot device that can be used to evaluate grapevine plants as described by Kicherer and coworker [16]. It was developed within the frame of a BMBF (Federal Ministry of Education and Research) funded project (PhenoVines FKZ: 0315968A of Projektträger Jülich) and is GPS guided. PHENObot carries a multi camera system but can also carry further sensors. Automated image analysis tools have been developed in cooperation with the project CROP.SENSe.net (FKZ: 0315534; BMBF, Projektträger Jülich) [16-19].

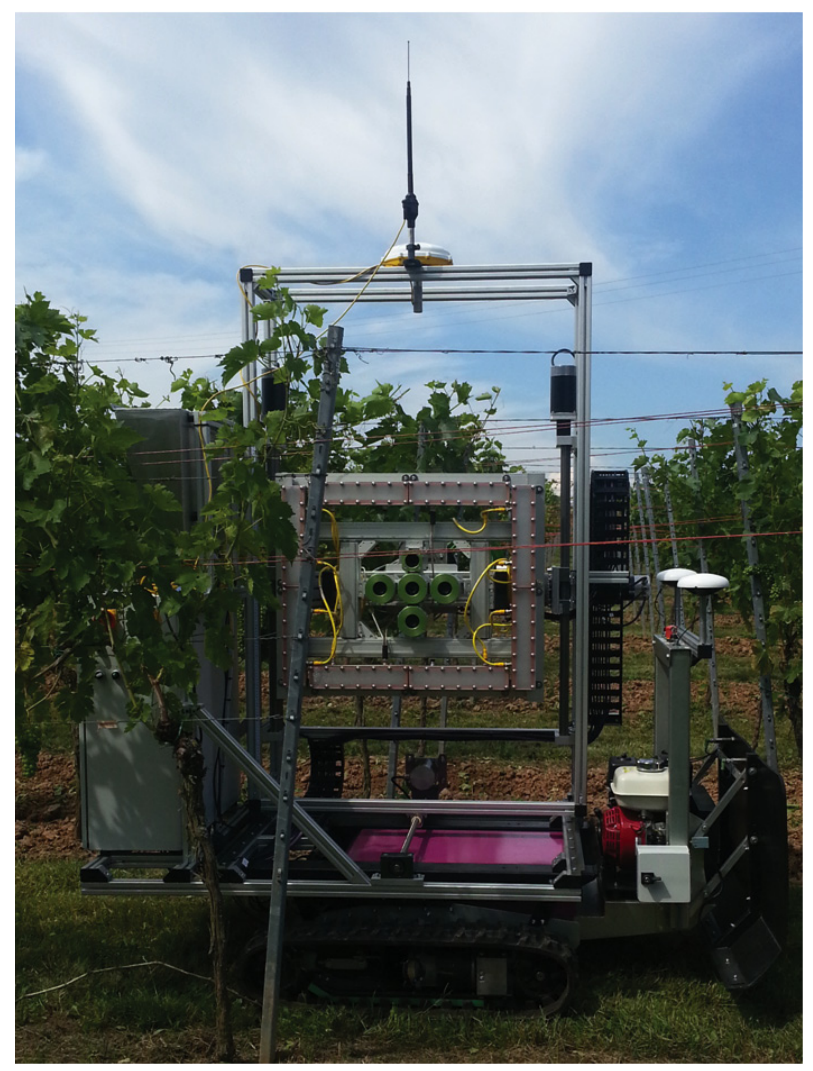

Figure 1. PHENObot is a system for rapid data acquisition along with a GPS track. Currently the system works image based but extension for further sensors is anticipated. 


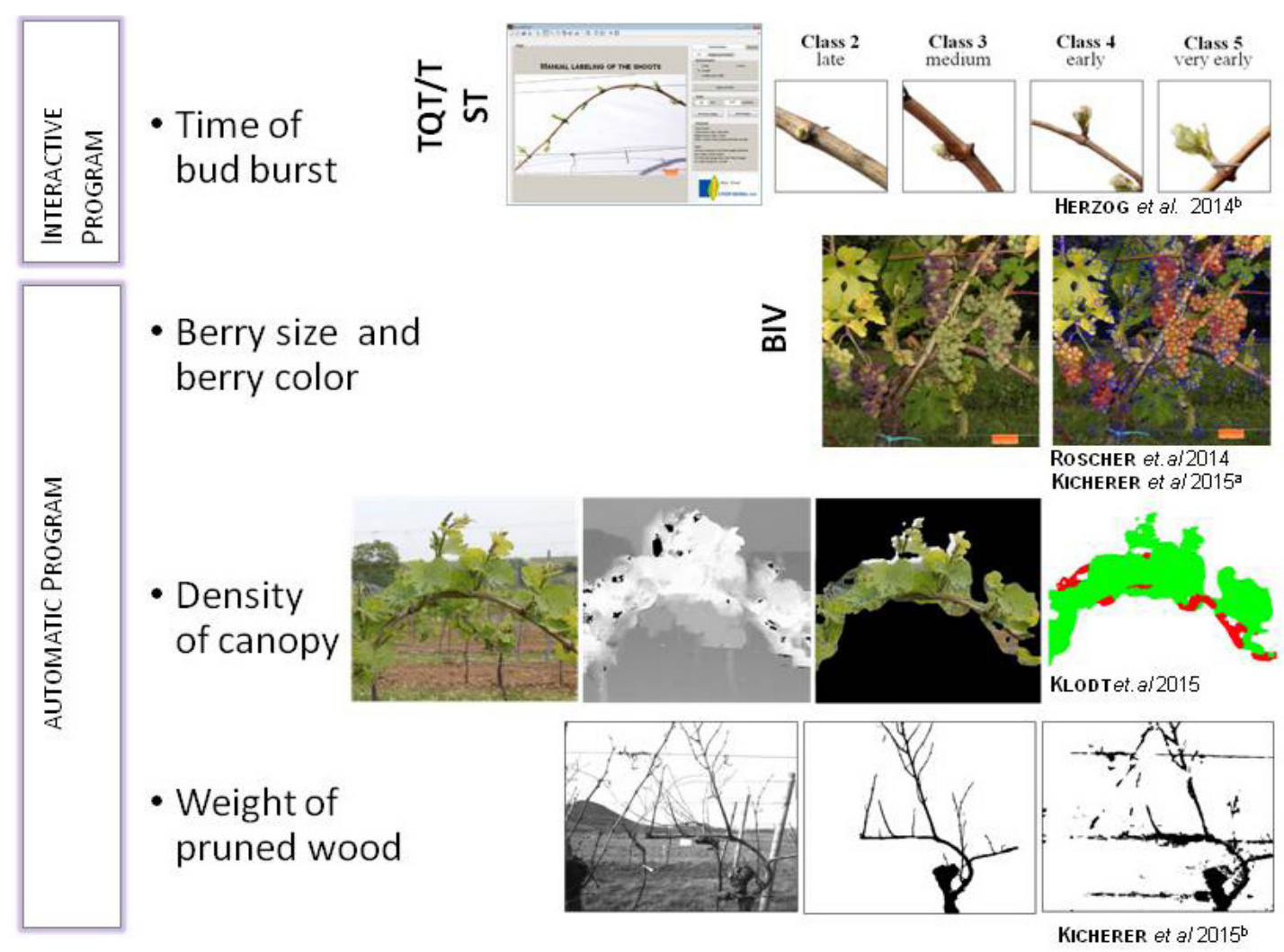

Figure 2. Current possibilities of high-throughput image based phenotyping for trait detection in vineyards. Four traits can be evaluated using sensor based techniques. Time of budburst is currently available as an interactive program while other traits can be analyzed in an automatic manner.

\section{Results and discussion}

Phenotyping in the field is a laborious task which is a daily business of grapevine breeders. Moreover, the screening on a single vine level is crucial in grapevine breeding [16]. Major traits which are recorded throughout the year are phenological traits (from bud burst to ripening), yield traits (berry size, number of berries per cluster, number of cluster per shoot, yield per vine), and resistances (e.g. powdery and downy mildew). Post-harvest evaluations consider composition of the grape juice, and finally after wine making the wine quality traits. Field evaluation is always limited by time with the consequence that a breeder has a deeper look into the breeding material only for advanced breeding strains hampering genetic studies on breeding populations. By using the PHENObot for the first time a large part of the grapevine collection at Geilweilerhof was evaluated for berry size and berry color at the same time [16]. In this field study images of 2700 plants representing 900 genotypes were captured within 13 hours and berry size and color was determined for each genotype which is at least 20 times faster than using manual power [16]. This first example of an automatic pipeline for field phenotyping and analysis of the raw data is very encouraging.

Some other traits that can be evaluated based on the images are indicated in Fig. 2 like bud burst [17], density of the canopy [19] or weight of the winter pruned wood [20]. Further yield parameters like the number of berries per vine [4] and the amount of fruit and leave pixels per image [21,22], have been evaluated image-based on a field level for practical viticulture purposes. The use of spectral sensor technologies in viticulture has been shown to provide information on vine vigor [12,13,23] and health status $[11,24]$. Whereas 3D approaches are mainly used for describing canopy size $[14,15]$ and dimensions [19].

The examples of the PHENObot and it's phenotyping pipeline shows the versatility of the system. They open the perspective for new applications to be developed and to increase the efficiency of grapevine breeding. However, for other traits interdisciplinary activities are required to establish similar fully automatic pipelines as described by Kicherer et al. [16]. Finally, further sensors or sensor fusion will increase the portfolio of phenotyping pipelines.

We gratefully acknowledge the financial support of the Federal Ministry of Education and Research (BMBF) and PT Jülich for the projects CROP.SENSe.net (FKZ: 0315534) and PhenoVines (FKZ: 0315968A).

\section{References}

[1] R. Eibach, E. Zyprian, L. Welter, R. Töpfer, Vitis 46, 120 (2007)

[2] F. Schwander, R. Eibach, I. Fechter, L. Hausmann, E. Zyprian, R. Töpfer, Theoretical and Applied Genetics 124, 163 (2012) 
[3] R. Töpfer, L. Hausmann, M. Harst, E. Maul, E. Zyprian, R. Eibach, New Horizons for Grapvine Breeding. In: Flachowsky, H.; Hanke M.-V. (Eds.) Methodes in Temperate Fruit Breeding. Fruit, Vegetable and Cereal Science and Biotechnology 5, (Special Issue 1), 79-100, Global Science Books (2011)

[4] S. Nuske, K. Wilshusen, S. Achar, L. Yoder, S. Narasimhan, S. Singh, Journal of Field Robotics 31, 837 (2014)

[5] M.P. Diago, A. Sanz-Garcia, B. Millan, J. Blasco, J. Tardaguila, Journal of the Science of Food and Agriculture 94, 1981 (2014)

[6] S. Fuentes, C. Poblete-Echeverría, S. Ortega-Farias, S. Tyerman, R. De Bei, Australian Journal of Grape and Wine Research 20, 465 (2014)

[7] S. Cubero, M.P. Diago, J. Blasco, J. Tardaguila, J.M. Prats-Montalbán, J. Ibáñez, J. Tello, N. Aleixos, Australian Journal of Grape and Wine Research 21, 101 (2015)

[8] S. Fuentes, W. Sullivan, J. Tilbrook, S. Tyerman, Australian Journal of Grape and Wine Research 16, 327 (2010)

[9] S. Fuentes, R. Bei, J. Pech, S. Tyerman, Irrigation Science 30, 523 (2012)

[10] H.G. Jones, R. Serraj, B.R. Loveys, L. Xiong, A. Wheaton, A.H. Price, Functional Plant Biology 36, 978 (2009)

[11] F. Mazzetto, A. Calcante, A. Mena, A. Vercesi, Precision Agriculture 11, 636 (2010)

[12] J. Llorens, E. Gil, J. Llop, M. Queralto, Sensors 11, $6237(2011)$

[13] D.W. Lamb, Australian Journal of Experimental Agriculture 40, 725 (2000)
[14] B. Grocholsky, S. Nuske, M. Aasted, S. Achar, T. Bates, ASABE Annual International Meeting (ASABE, Louisville, Kentucky, 2011)

[15] Tagarakis, L. Perlepes, V. Liakos, S. Fountas, P. Kikiras, T. Gemtos, Application of precision agriculture in vines $\mathbf{3 0 3}$ (2010)

[16] Kicherer, K. Herzog, M. Pflanz, M. Wieland, P. Rüger, S. Kecke, H. Kuhlmann, R. Töpfer, Sensors 15 (3), 4823 (2015a)

[17] K. Herzog, A. Kicherer, R. Töpfer, 11th International Conference on Grapevine Breeding and Genetics. (International Society for Horticultural Science (ISHS), Beijing, China, 2014), submitted.

[18] R. Roscher, K. Herzog, A. Kunkel, A. Kicherer, R. Töpfer, W. Förstner, Computers and Electronics in Agriculture 100, 148 (2014)

[19] M. Klodt, K. Herzog, R. Töpfer, D. Cremers (2015) BMC Bioinformatics, 16:143 DOI:110.1186/ s12859-12015-10560-x. (2015)

[20] Kicherer, M. Klodt, S. Sharifzadeh, D. Cremers, R. Töpfer, K. Herzog, Australian Journal of Grape and Wine Research, submitted (2015b)

[21] M.P. Diago, C. Correa, B. Millán, P. Barreiro, C. Valero, J. Tardaguila, Sensors 12, 16988 (2012)

[22] G.M. Dunn, S.R. Martin, Australian Journal of Grape and Wine Research 10 (3), 196 (2004)

[23] F. Mazzetto, A. Calcante, A. Mena, P. Sacco, Journal of Agricultural Engineering 42, 1 (2011)

[24] S. Lejealle, G. Bailly, G. Masdoumier, J.L. Ayral, $\mathrm{G}$. Latouche, Z. Cerovic, 10e Conférence Internationale sur les Maladies des Plantes, (Association Française de Protection des Plantes (AFPP): pp. 63 (2012) 